\title{
OnabotulinumtoxinA for treatment of chronic migraine: PREEMPT 24-week pooled subgroup analysis of patients without medication overuse
}

\author{
HC Diener ${ }^{1 *}$, DW Dodick², RE DeGryse ${ }^{3}$, CC Turkel $^{3}$ \\ From The European Headache and Migraine Trust International Congress \\ London, UK. 20-23 September 2012
}

\section{Introduction}

$\mathrm{CM}$ is a prevalent, disabling primary headache disorder. Most patients in CM clinical trials overuse AHM. The efficacy of prophylactic medications in CM patients without overuse of AHM is unclear.

\section{Objective}

To evaluate the efficacy and tolerability of onabotulinumtoxin A in a chronic migraine $(\mathrm{CM})$ subgroup without acute headache medication (AHM) overuse (MO-No).

\section{Design/methods}

PREEMPT (two phase 3 studies: 24-week, double-blind, placebo-controlled, parallel-group phase, followed by $32-$ week, open-label phase) evaluated onabotulinumtoxinA for prophylaxis of headaches in CM ( ${ }_{\mathrm{i}} \mathrm{Y} 15$ days/month with headache lasting $i \hat{Y} 4$ hours/day). Patients were stratified based on AHM use during 28-day baseline and randomized (1:1) to onabotulinumtoxinA (155-195U) or placebo every 12 weeks. Multiple headache-symptom measures were evaluated at Week 24, including mean change from baseline in headache-day frequency (primary). Pooled results from MO-No subgroup are reported.

\section{Results}

480 ( $\mathrm{n}=243$ onabotulinumtoxinA; $\mathrm{n}=237$ placebo) of 1384 patients met MO-No criteria. At Week 24, onabotulinumtoxinA treatment significantly reduced headache-day frequency compared to placebo (-8.8/onabotulinumtoxinA; -7.3/placebo: $\mathrm{p}=0.013$ ). Significant improvements from baseline $\left(p_{i} U ̈ 0.027\right)$ also favored onabotulinumtoxinA at Week 24 for frequency of migraine-days, moderate/severe headache-days, total cumulative hours of headache on headache-days, and percent of patients with severe $(i Y 60)$ headache impact test (HIT-6) scores. Improvements in total HIT-6 and migraine-specific questionnaire scores all significantly favored onabotulinumtoxinA over placebo at Week 24 (pi $\mathrm{U} 0.032$ ). Few patients in this subgroup discontinued because of an adverse event (AE); AEs were consistent with overall PREEMPT tolerability.

\section{Conclusion/relevance}

OnabotulinumtoxinA is effective and well-tolerated for prophylaxis of headache in CM patients who do not overuse AHM.

\section{Support}

Allergan, Inc.

Author details

${ }^{1}$ University of Essen, Dept. of Neurology, Essen, Germany. ${ }^{2}$ Mayo Clinic Arizona, Dept. of Neurology, Phoenix, AZ, USA. ${ }^{3}$ Allergan, Irvine, CA, USA.

Published: 21 February 2013

\section{doi:10.1186/1129-2377-14-S1-P204}

Cite this article as: Diener et al.: OnabotulinumtoxinA for treatment of chronic migraine: PREEMPT 24-week pooled subgroup analysis of patients without medication overuse. The Journal of Headache and Pain 2013 14(Suppl 1):P204.

${ }^{1}$ University of Essen, Dept. of Neurology, Essen, Germany

Full list of author information is available at the end of the article

(C) 2013 Diener et al; licensee Springer. This is an Open Access article distributed under the terms of the Creative Commons Attribution License (http://creativecommons.org/licenses/by/2.0), which permits unrestricted use, distribution, and reproduction in any medium, provided the original work is properly cited. 